\title{
sala

\section{HISTORIOGRAFIA DA CIÊNCIA E LINGUAGEM INFOGRÁFICA: PONTUAÇÕES À FORMAÇÃO DE PROFESSORES DE CIÊNCIAS}

\section{HISTORIOGRAPHY OF SCIENCE AND INFOGRAPHIC LANGUAGE: APPOINTMENTS TO THE FORMATION OF SCIENCE TEACHERS}

\author{
Taís de Souza Silva \\ Universidade Federal do Paraná, Palotina, Paraná \\ E-mail: taissouza0705@gmail.com \\ Lucas Mota Costa \\ Universidade Federal do Paraná, Palotina, Paraná \\ E-mail: lucasmadotate@gmail.com \\ Leandro Siqueira Palcha \\ Universidade Federal do Paraná, Palotina, Paraná \\ E-mail: leandropalcha@gmail.com
}

\begin{abstract}
Resumo: $\mathrm{O}$ artigo discute o desenvolvimento de um infográfico como estratégia pedagógica para abordar a historiografia da ciência no Ensino de Ciências. Fundamenta-se em autores que discutem a importância da historiografia na formação de professores e da relação de tecnologias digitais para o processo de aprendizagem da ciência. O objetivo principal é realizar pontuações sobre a historiografia da ciência e linguagem infográfica para a formação de professores de Ciências. Em termos metodológicos, a pesquisa foi realizada na disciplina de "História, Filosofia e Ensino das Ciências", do curso de Licenciatura em Ciências Exatas. O infográfico analisado aqui tem enfoque na Mecânica Newtoniana e Mecânica Relativista e foi construído por meio do auxílio de aplicativos voltados para o contexto educativo. Pontua-se que a infografia favorece a autoria dos professores em formação a criar materiais didáticos, bem como permite ao aluno ser protagonista da aprendizagem ajudando-Ihe na compreensão da história da ciência.
\end{abstract}

Palavras-chave: História da ciência. Ensino de Ciências. Formação de professores. Tecnologia digital.

Abstract: This article discusses the development of infographics as a pedagogical strategy. It was based on authors who discuss the importance of historiography in teacher education and the relationship between digital technologies and the science learning process. In methodological terms, the research was carried out in the discipline of "History, Philosophy, and Teaching of Sciences" of the course of a Licenciatura degree in Exact Sciences. The infographic analyzed here has focused on Newtonian Mechanics and Relativistic Mechanics. It is noted here that the infographic language favors the authorship of teachers in training when creating teaching materials, as well as allowing the student to be the protagonist of their learning. The creation of the infographic helped students to understand the history of science.

Keywords: History of science. Science Teaching. Teacher education. Digital technology. 


\section{sala \\ de $\oplus$ - em \\ aula foco}

\section{HISTORIOGRAFIA E INFOGRAFIA: UMA INTRODUÇÃO PARA ENSINAR CIÊNCIA}

Nos dias atuais, sabe-se que muitos alunos dispõem de diversas tecnologias digitais que podem ser usadas para se apropriar de inúmeras informações que circulam em nossa sociedade. No entanto, apenas ter uma gama de informações não garante que esses alunos consigam construir explicações científicas com respaldo em fontes seguras. O que traz implicações à formação de professores.

Importa que as práticas educativas construam inter-relações com a cultura digital a fim de trabalhar e mobilizar os conhecimentos produzidos que vão para além dos muros da escola. Segundo Camargo e Daros (2018, p. 17), "a metodologia de ensino tradicional mostra-se inconsistente com a necessidade atual, ou seja, o modelo atual apresenta-se saturado e os resultados apresentados por ele não se dão de modo satisfatório". Além disso, os autores indicam que "a metodologia ativa de aprendizagem apresenta-se como uma forma de preencher essa lacuna ou campo demandado e pouco explorado" (CARMARGO; DAROS, 2018, p. 17).

Abordar a história da ciência em sala de aula, nesse contexto, implica mostrar que "a ciência não brota pronta, na cabeça de grandes gênios. Muitas vezes, as teorias que aceitamos hoje foram propostas de forma confusa, com muitas falhas, sem possuir uma base observacional e experimental" (MARTINS, 2006, p. 17).

De acordo com Gatti e Nardi (2016, p. 17), existe uma real preocupação de alguns pesquisadores em "testar em sala de aula experiências embasadas em referenciais teóricos. Não só relacionados à questão da aproximação da HFC ao ensino, mas também aqueles que discutem como a prática de ensino de futuros professores e professoras em exercício são afetadas", ou seja, quando trabalham por uma perspectiva inovadora.

Entendemos, assim, que o uso da historiografia da ciência pode contribuir para a construção de uma visão da ciência para os professores de Ciências em formação. A historiografia "é composta 


\section{sala \\ de $\oplus$ - em \\ aula foco}

essencialmente por textos escritos e reflete sobre os acontecimentos históricos agregando-lhes um caráter discursivo novo" (MARTINS, 2004, p. 116).

Já para Beltran, Saito e Trindade (2014), a historiografia vincula-se a visão de mundo do sujeito que a desenvolve, pois para analisar a história de como as coisas realmente ocorreram, de como as teorias foram edificadas, isso: "significa que as narrativas históricas não são neutras e são influenciadas por diferentes fatores ligados não só à formação, mas também à concepção de ciência daquele que escreve a história" (BELTRAN; SAITO; TRINDADE, 2014, p. 31).

Deve-se ter em mente que o uso de aplicativos em salas de aula se associa, basicamente, a uma demanda da sociedade tecnológica. "Os aplicativos são programas de computador concebidos para processar dados eletronicamente. Têm como intuito facilitar e reduzir o tempo de execução de uma tarefa pelo usuário, bem como proporcionar o acesso a novos conhecimentos de uma forma diferenciada" (CAMARGO; DAROS, 2018, p. 28)

Assim, este artigo procura relacionar o ensino da história da ciência ao uso de aplicativos para a construção de infográficos, como uma possibilidade de representar/visualizar uma informação. Para melhor entender, o infográfico é um conjunto de textos, informações ligadas à imagens, gráficos, mapas entre outras possibilidades de mídias (ARAÚJO; COSTA; FIREMAN, 2015). Tal modo de representação/comunicação fornece uma visão geral e dinâmica da leitura, bem como se pode usá-lo para mediação didática de determinado conteúdo científico, mostrando aos alunos a sequência lógica de um determinado conteúdo e fazendo com que este acompanhe o raciocínio ali apresentado.

Partimos do princípio, então, que a "História da Ciência é o estudo da(s) forma(s) de elaboração, transformação e transmissão de conhecimentos sobre a natureza, as técnicas e as sociedades, em diferentes épocas e culturas" (BELTRAN; SAITO; TRINDADE, 2014, p. 15).

Nesses termos, há diferentes possibilidades teóricas e estratégias pedagógicas para discutir a História da Ciência no contexto educativo e, como asseguram Carvalho e Gil-Pérez (2011), um 


\section{sala \\ de $\oplus$ - em \\ aula foco}

professor precisa conhecer a história das ciências, não só como aspecto básico da cultura científica, mas como uma forma de associar os conhecimentos científicos com os problemas que originaram a sua construção. Por isso, neste artigo, escolhemos introduzir aspectos sobre a historiografia das ciências aliada a tecnologias digitais na formação de professores, como forma de atrair o interesse dos estudantes aos tópicos historiográficos atuais durante as aulas.

Ao estudar a historiografia das ciências nota-se que sua narrativa é construída com o passar do tempo, que não é algo pronto, acabado, mas que possibilita interpretação. Por assim dizer, "abordagem historiográfica propõe mapear e contextualizar os conhecimentos do passado, considerando-se não só as continuidades, mas também as descontinuidades" (BELTRAN; SAITO; TRINDADE, 2014, p. 46).

Em nosso caso, analisando que os aplicativos vêm sendo amplamente utilizados buscamos problematizar a relação entre a História da Ciência e a construção de infográficos por meio de aplicativos. Conforme Camargo e Daros (2018, p.28) "o uso de aplicativos em contextos educacionais é capaz de proporcionar diferentes possibilidades de trabalho pedagógico de modo significativo". Mas, argumentam que "essas novas tecnologias digitais precisam ser utilizadas de maneira criativa e também crítica, buscando adequar seus usos aos conteúdos necessários" (CAMARGO; DAROS, 2018, p. 28).

No que compete a este estudo, procuramos destacar a construção de um infográfico para mediação didática de conteúdos historiográficos na área da Física focando a atenção para a temática da Mecânica, por meio de duas importantes teorias: a Mecânica Newtoniana e outra denominada Mecânica Relativista. Com isso, decidiu-se colocá-las lado a lado, destacando os principais pontos de cada uma.

Retomemos aqui que a Mecânica Newtoniana foi criada por Isaac Newton, no final do século XVII, e fornece uma lista de leis que podem ser aplicadas e a partir desta deduzir as outras (NUNES, 2003). Newton, com essas leis e suas descrições matemáticas sobre o Universo, deu início a uma nova fase na ciência, iniciando uma Revolução Científica (PORTO; PORTO, 2008). 


\section{sala \\ de $\oplus$ - em \\ aula foco}

Em 1905, Einstein baseando-se nos problemas da teoria de Newton, bem como confrontando a ciência de sua época, formulou uma teoria que visava discutir os conflitos que existiam na Física. Defendeu o princípio da relatividade de Galileu, dizendo que deveria ser mais abrangente, ou seja, aplicável para todas as leis da Física (BRAGA; GUERRA; REIS, 2007) e refutou-se às leis criadas por Newton. Einstein também formulou dois postulados (axiomas), nomeando toda a teoria de Teoria da Relatividade Restrita (TRR).

Einstein ficou conhecido pela construção dessa teoria, antes, porém alguns pesquisadores já haviam pensado sobre o tema, como Heinrich Hertz, Joseph Larmor, Max Abraham e Hendrik Antoon Lorentz, porém estes em sua época não tinham aparelhagem experimental adequada. Já no tempo em que Einstein estudou essas teorias foi possível analisá-las melhor, facilitando a construção da mesma (MARTINS, 2005).

Portanto, este artigo nos impele a problematizar se a linguagem infográfica contribui para explicar/associar de forma breve a História da Ciência e, com isso, discutir: i) as possibilidades de os alunos aprenderem como as teorias já conhecidas foram desenvolvidas; ii) se os cientistas renomados e citados pelo infográfico desenvolveram as teorias de modo contínuo; ou ainda, iii) se somente um estudioso criou toda a teoria, como um grande gênio.

O tema abordado pelo infográfico, objeto deste estudo, refere-se a Mecânica Newtoniana e Mecânica Relativista, sendo estas teorias explicadas de forma dinâmica e atrativa. Já o objetivo principal do estudo é realizar pontuações didáticas sobre a historiografia da ciência e a linguagem infográfica para a formação de professores de Ciências. Espera-se, portanto, trazer alguns indicativos para ampliar e aprofundar as discussões sobre história e filosofia da ciência na formação de professores. 


\section{sala \\ de $\oplus$ - em \\ aula foco}

\section{PROCEDIMENTOS METODOLÓGICOS}

O presente estudo foi desenvolvido na disciplina de "História, Filosofia e Ensino das Ciências", em uma turma do quarto período, do curso de Licenciatura em Ciências Exatas, de uma universidade pública, no primeiro semestre de 2018.

Como requisito da disciplina, os licenciandos precisavam desenvolver em duplas um infográfico $(90 \mathrm{~cm} \times 60 \mathrm{~cm})$, para um conceito ou abordagem temática pertinente à historiografia da ciência, tendo como público alvo os alunos do Ensino Médio. Com efeito, a atividade encontra amparo nos dizeres de Carvalho e Gil-Pérez (2011), quando os autores sugerem que se quisermos uma mudança didática na formação de professores, devemos começar por vivenciar propostas inovadoras e análise crítica delas.

O corpus de análise, deste artigo de pesquisa, se constitui por um infográfico envolvendo as teorias relacionadas a Mecânica, produzidos pelos primeiros autores do trabalho. A natureza do estudo é de abordagem qualitativa (LUDKE; ANDRE, 2016) priorizando uma análise e reflexão sobre o objeto de estudo para o contexto educativo.

Para construção do infográfico, foi realizado um estudo sobre o tema, buscando por literaturas primárias ou secundárias de fontes confiáveis e atualizadas, as quais foram utilizadas como postos-chaves para o infográfico. Na sequência, procurou-se por métodos digitais para desenvolver o infográfico, dentre as opções há sites, como: Canva, Piktochart, Easel.ly, Visme, Infogr.am, entre outros.

O software online escolhido para criar o trabalho, foi o Canva, pois fornece a possibilidade de compartilhamento entre os membros da equipe, deste modo, cada um consegue acessar de qualquer lugar que tenha internet e em qualquer computador usando o seu endereço de e-mail. No site existe a possibilidade de vários designers e é possível editar um pronto, ou criar um design próprio, a qual foi decidido criar um próprio, buscando organizá-lo de forma dinâmica e atrativa. 


\section{sala \\ de $\oplus$ - em \\ aula foco}

Para deixar o infográfico mais atrativo, adicionaram-se pequenas imagens relacionadas à Física em seu topo e, após uma faixa, foi escrito o tema, descendo de dois lados, em que em um tratase da teoria de Newton e no outro a teoria de Einstein, em que cada respectivo lado contém pontos de destaque das teorias. Para concluir, usaram-se círculos grandes, pequenos e médios, em que nos médios contém as fórmulas criadas pelos pensadores e no maior uma conclusão geral entre os dois.

No fluxograma a seguir, Figura 1, está esquematizado de forma resumida todo o processo de construção do infográfico e que fora descrito anteriormente, lembrando que este é uma proposta de como realizar essa construção, podendo ser alterada de acordo com a pessoa ou equipe, com a necessidade de cada um, ou melhor ainda, cada um pode desenvolver um modo inovador e próprio.

Figura 1: Fluxograma de trabalho

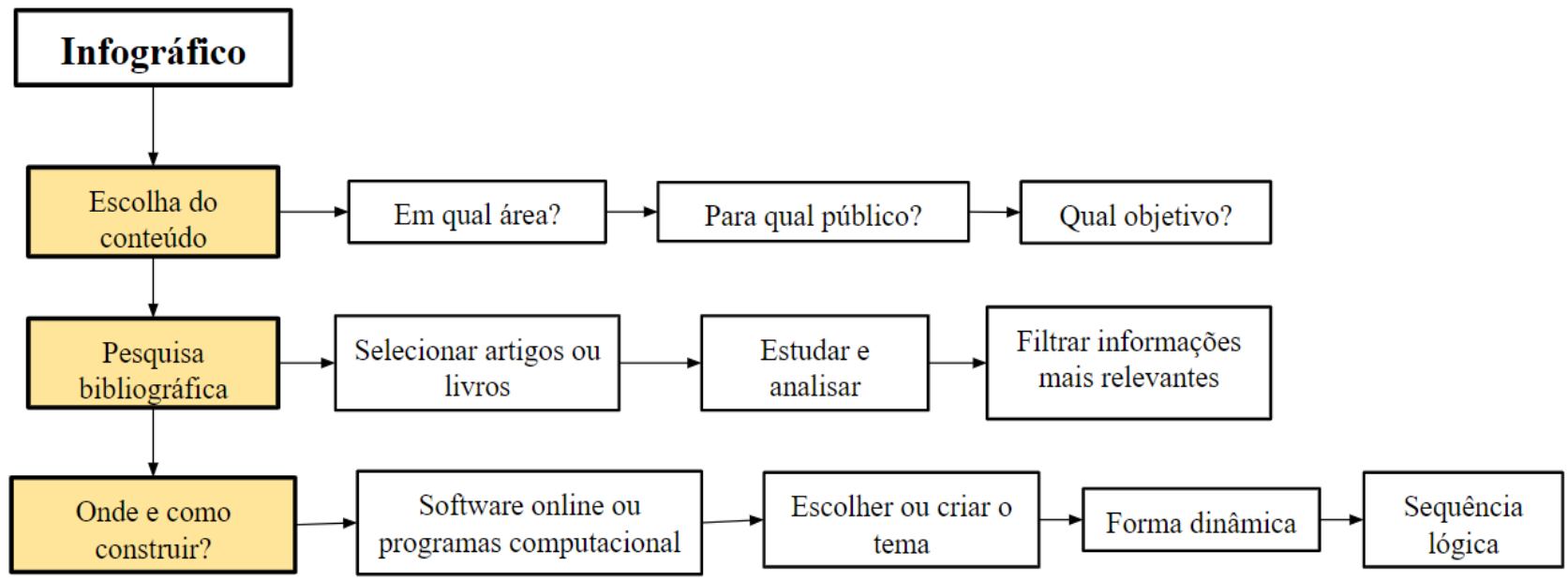

Fonte: Os autores (2018)

Os procedimentos analíticos orientam-se pelo referencial metodológico da Análise de Conteúdo (BARDIN, 2016), pelo qual o pesquisador deve analisar, sistematizar, inferir e produzir uma interpretação da pesquisa que leva a uma forma de apresentação e discussão dos dados. Assim, destacaremos pontos pertinentes que compõem o infográfico e posteriormente apresentaremos algumas de nossas análises. 


\section{sala \\ de $\oplus$ - em \\ aula foco}

Mecânica Newtoniana e Relativista na linguagem infográfica: a historiografia da ciência em análise

O infográfico envolvendo os conceitos da mecânica é apresentado pela Figura 2. Antes apresentamos, algumas considerações que foram de extrema importância para a sua elaboração.

O primeiro ponto abordado é que, segundo Newton, a massa é pontual e constante, independentemente da velocidade em que se encontra, sendo representada por: $m=\frac{d p}{d}$.

Considerando que um pequeno fragmento está livre e não sofre ação de nenhuma força ou que a força resultante seja nula. Esse fragmento encontra-se em um referencial inercial, se estiver em repouso ou em movimento retilíneo com velocidade constante, ou melhor, a partícula adequase às três leis de Newton, por isso temos um referencial inercial, e que a partir destes torna-se possível encontrar outros referenciais inerciais, desde que, o fragmento encontra-se nas condições descritas (RIFFEL, 2010).

Outro conceito abordado é a descrição do espaço, em que, segundo Newton este se encontra em três dimensões (largura, altura e comprimento) e o tempo é uma concepção independente (espaço absoluto e tempo absoluto), ou seja, o espaço absoluto sempre permanecia estático, por conta da sua natureza, sem relacionar-se a qualquer corpo externo. O tempo absoluto possuía as mesmas propriedades, sempre emancipado do lugar em que do universo encontrava-se, sendo ele unidimensional, infinito e sem interrupções, fluindo igualmente para qualquer acontecimento físico não havendo interferência externa (RIFFEL, 2010). Na teoria da Mecânica Relativista, o primeiro ponto abordado no infográfico também foi a massa, em que, segundo Einstein, é dada por: $m=$

$\frac{m{ }^{\prime}}{\sqrt{1-\frac{v^{2}}{c^{2}}}}$, onde $m^{\prime}$ é a massa inicial do corpo, $v$ a velocidade, e $c$ a velocidade da luz. Ao analisar a expressão acima, podemos ver que a massa $(m)$ é diretamente proporcional à velocidade do corpo, deste modo, se a velocidade aumenta a massa do corpo também aumentará, ou seja, a massa irá variar de acordo com o seu referencial inercial (RIFFEL, 2010 ). 


\section{sala \\ de $\oplus$ em \\ aula foco}

Einstein propôs também dois postulados em sua teoria. O primeiro postulado proposto, afirma que: "Todos os observadores inerciais são equivalentes", ou melhor, não existe um referencial privilegiado entre todos os referenciais inerciais, pois tanto a velocidade quanto a posição tornam-se conceitos relativos, por não ser possível determinar o absoluto, com isso, a noção de espaço absoluto chega ao fim.

Já o segundo postulado anuncia que: "A velocidade da luz é a mesma em todos os referenciais de inércia", ou seja, a velocidade da luz é invariável, sendo igual em todas as direções em um dado referencial, não dependendo da fonte em que a emite (RIFFEL, 2010). Einstein utilizou uma consequência imposta por Maxwell, em que, por meio de suas equações determinou que a propagação da luz no vácuo é $3 \times 10^{8} \mathrm{~ms}^{-1}$, relativamente em um sistema de inércia definido (S), então, admitiu isso para qualquer outro sistema de inércia (NUNES, 2003).

Para Einstein, o espaço é composto por largura, comprimento, altura e tempo, dimensões $x, y, z$ e $t$, sendo o tempo relativo, ou seja, o tempo torna-se uma variável, não mantendo-se estático, ao contrário de Newton, que relata que o tempo é algo absoluto e imutável.

Ainda, é importante lembrar que as teorias se complementam, ou seja, a teoria da mecânica clássica está ligada com a teoria da mecânica relativista, em outras palavras, a mecânica clássica possui um certo limite, não sendo aplicável a todos os fenômenos, já a teoria da mecânica relativista abrange todo o universo, explicando diversos acontecimentos que a outra não consegue, como ilustrado na Figura 3. 


\section{sala \\ de $\oplus$ em \\ aula foco}

Figura 2: Infográfico sobre a Mecânica

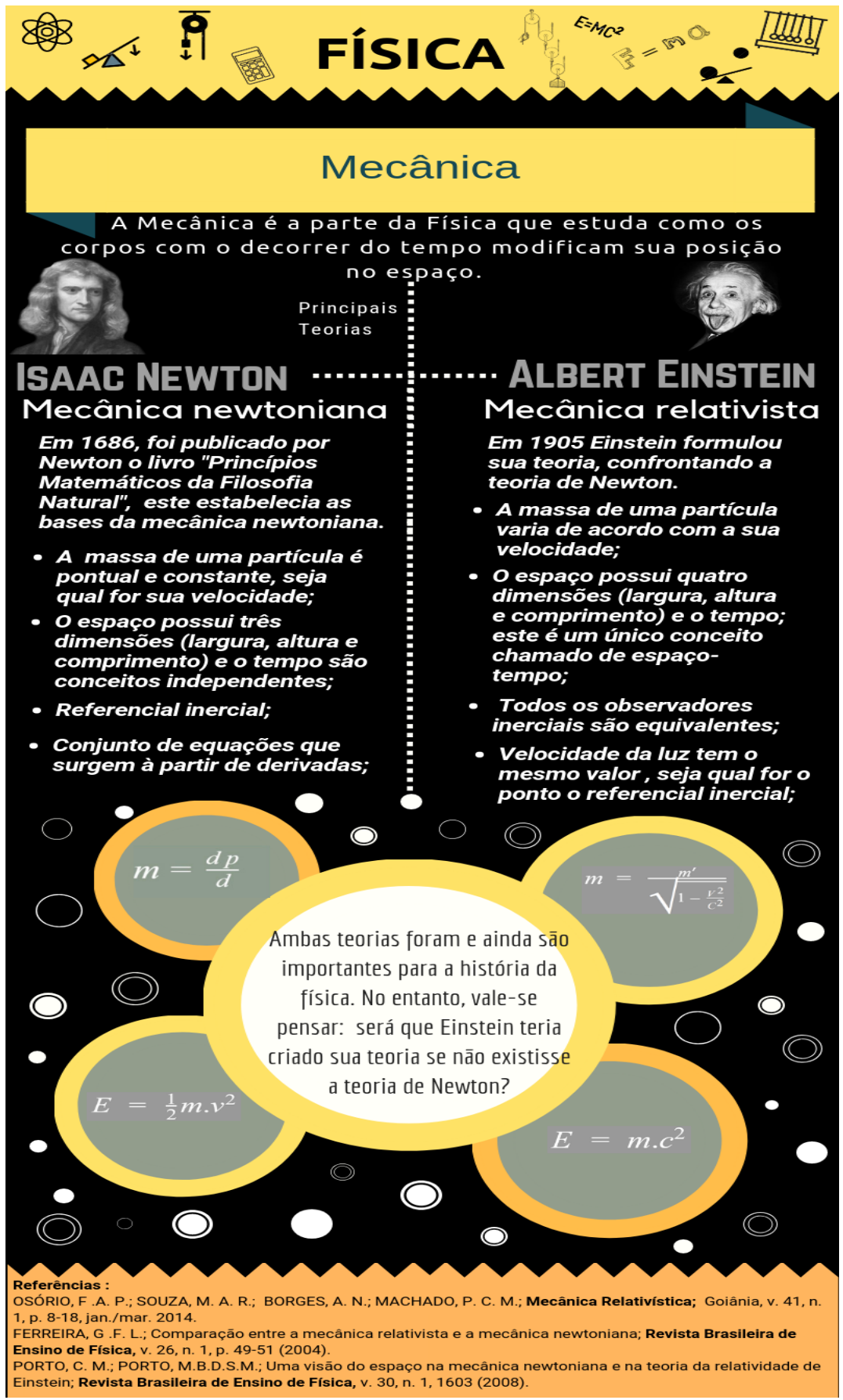

Fonte: Os autores (2018) 


\section{sala \\ de $\oplus$ em \\ aula foco}

Figura 3: llustração da relação entre as teorias

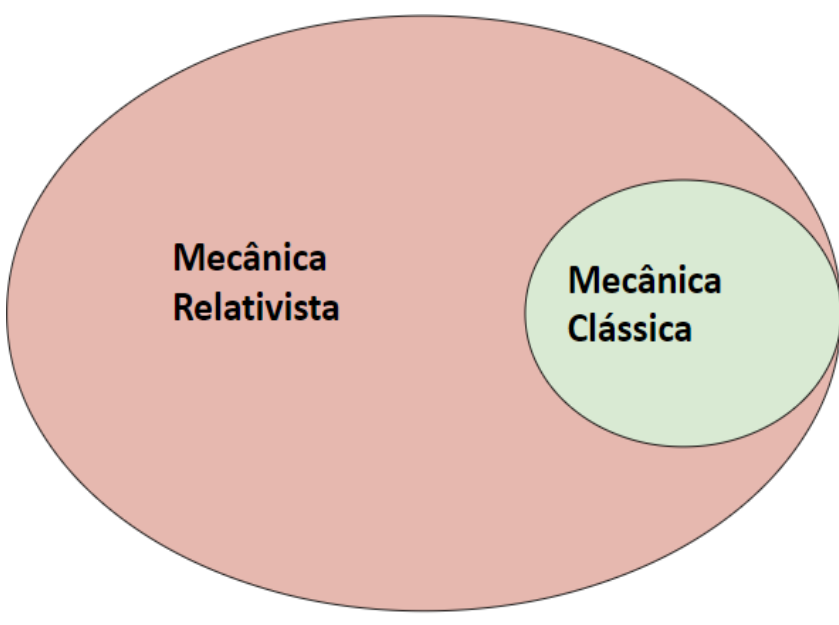

Fonte: Os autores (2018)

No geral, podemos dizer que o infográfico traz aspectos históricos que mostram uma abordagem para construção do conhecimento científico. Mostra também como "o conhecimento científico é um constante jogo de hipóteses e expectativas lógicas, um constante vaivém entre o que pode ser e o que "é", uma permanente discussão e argumentação/contra argumentação entre teoria e observações e as experimentações realizadas" (PRAIA; CACHAPUZ; GIL-PÉREZ, 2011, p. 93).

Com isso, defendemos que é necessário para ensinar ciência que os professores assumam uma concepção do que é ciência e como ministrá-la de modo dinâmico, revelando os pontos e contrapontos. Em suma, uma concepção que envolva o aluno como protagonista da aprendizagem, seja dinâmica e relacionada à sociedade que a constitui, para isto torna-se indispensável que os professores possuam uma formação adequada. Já que: "a história das ciências não pode substituir o ensino comum das ciências, mas pode complementá-lo de várias formas" (MARTINS, 2006, p. 17).

Consideramos que o infográfico apresenta informações pertinentes a uma leitura dinâmica e atrativa que possibilita aos alunos se aprofundar posteriormente sobre o desenvolvimento historiográfico de ambas as teorias. O infográfico foi exposto no mural do laboratório de ensino da universidade e, doravante, pretendemos desenvolver a construção de infográficos com professores 


\section{sala \\ de $\oplus$ - em \\ aula foco}

e alunos da educação básica, afixando os infográficos no espaço escolar de modo a instigar a outros sujeitos a procurar ou acrescentar mais informações sobre os conhecimentos físicos.

Por fim, salientamos que "o conceito de formação tem a ver com a capacidade de formação, assim como a vontade de formação. Quer dizer, é o indivíduo, a pessoa, o responsável último pela ativação e desenvolvimento de processos formativos" (GARCÍA, 1999, p. 22). Dessa forma, neste trabalho, apresentamos uma possibilidade que não depende apenas de nossa vontade de transformar a realidade do ensino, mas desta e outras possibilidades para que juntos possamos buscar uma mudança didática significativa nas práticas de formação de professores.

\section{PONTUAÇÕES À FORMAÇÃO DE PROFESSORES}

O estudo da historiografia das teorias envolvidas, no presente artigo, demonstra uma possibilidade de ampliar a visão sobre a abordagem histórica da ciência por meio da linguagem infográfica, realçando a contribuição de variados pensadores ao decorrer do tempo, construindo-a gradualmente e não subitamente como se poderia pensar.

Há de ser considerado, preliminarmente, a possibilidade de conduzir a autoria aos professores de Ciências sobre os recursos didáticos que fazem parte da mediação didática de conteúdos científicos. A construção deste infográfico mostra que é possível utilizar materiais diferentes para trabalhar nas aulas, os quais podem ser construídos ao longo das aulas, contextualizando o Ensino de Ciências a contemporaneidade tecnológica em que vivemos.

Conforme García (1999), pontuamos que os processos de mudança e de formação de professores devem ser pensados em conjunto, a fim de que sejam valorizados e integrados ao desenvolvimento curricular. Assim, esses processos ganham visibilidade e qualidade uma vez que existe a projeção de novos profissionais que formarão outros que atendem a uma demanda da sociedade.

Para Carvalho e Gil-Pérez (2011, p. 20) é necessário orientar a atividade docente "como um trabalho coletivo de inovação, pesquisa e formação permanente". Por assim dizer, por meio de nosso 


\section{sala \\ de $\oplus$ - em \\ aula foco}

trabalho, assinalamos também a importância de explorar a criatividade do trabalho do professor, sobretudo, de forma coletiva com a turma, uma vez que o trabalho isolado e solitário pode não resultar em uma mudança didática para a educação que tanto desejamos.

Vale pontuar, ainda, que buscar a colaboração dos alunos é fundamental para se criar um espaço coletivo e interconectado com a produção do conhecimento científico. Colocando-o aluno como protagonista da aprendizagem, ao construir um infográfico, também, registra-se a oportunidade de ele refletir sobre a historiografia da ciência, pesquisando por informações em fontes seguras, selecionando os principais aspectos a serem destacados e divulgar seu conhecimento aos colegas.

A formação de professores, pensada assim, pode trazer indicativos positivos e significativos a Educação em Ciências que se constrói na contemporaneidade, uma vez que traz a participação dos alunos, a interconectividade das tecnologias digitais, e o conhecimento histórico das ciências. Tratase, em suma, de "usar a formação como um processo de pesquisa efetuando investigação com os professores, com vista a que tal produção de saberes seja reinvestida na inovação para que esta, persistentemente, se venha a transformar em mudança" (PRAIA; CACHAPUZ; GIL-PÉREZ, 2011, p. 102).

Resta dizer que o estudo da linguagem infográfica e da historiografia da ciência pode ser aprofundado em trabalhos posteriores e principalmente, levando em conta estas pontuações para a aplicabilidade de infográficos no contexto escolar.

\section{REFERÊNCIAS}

ARAÚJO, T.M. S.; COSTA, J. E. V. L.; FIREMAN, E.C. A Infografia nas aulas de Ciências como estratégia pedagógica para aquisição da aprendizagem significativa; In: Congresso Nacional de Educação, 2. Anais... Campina Grande -PB, 2015, p.1-13

BARDIN, L. Análise de Conteúdo. 3a Reimpressão. São Paulo: Edições 70, 2016.

BELTRAN, M. H. R.; SAITO, F.; TRINDADE, L. S. P. A História da Ciência para formação de professores. São Paulo; Editora Livraria da Física, 2014. 


\section{sala \\ de $\oplus$ - em \\ aula foco}

REVISTA ELETRÔNICA

BRAGA, M.; GUERRA, A.; REIS, J. C. Teoria da relatividade restrita e geral no programa de mecânica do ensino médio: uma possível abordagem. Revista Brasileira de Ensino de Física; v. 29, n. 4, p. 575583, 2007.

CAMARGO, F.; DAROS, T. A sala de aula inovadora: estratégias pedagógicas para fomentar o aprendizado ativo. Porto Alegre: Penso, 2018.

CARVALHO, A. M. P.; GIL-PÉREZ, D. A formação de professores de Ciências: tendências e inovações. 10.ed. São Paulo: Cortez, 2011.

GARCÍA, C. M. Formação de professores: para uma mudança educativa. Porto: Ed. Porto, 1999.

GATTI, S. R. T.; NARDI, R. A História e a Filosofia da Ciência no Ensino de Ciências: a pesquisa e as contribuições para a prática pedagógica em sala de aula. São Paulo: Escrituras, 2016

LUDKE, M. ANDRÉ, M.E.D.A. Pesquisa em educação: abordagens qualitativas. 2.ed. São Paulo: EPU, 2016.

MARTINS, R. A. Física e história. Ciência e Cultura, vol. 57, n. 3, 2005.

MARTINS, R. A. Introdução: A história das Ciências e seus usos na educação. In: SILVA, C. C. (org.) Estudos de História e Filosofia das Ciências: subsídios para aplicação no ensino. São Paulo: Livraria da Física, 2006. p. 17-30.

MARTINS, R. A. Ciência versus historiografia: os diferentes níveis discursivos nas obras sobre a história da ciência. In: ALFONSO-GOLDFARB, A.M.; BELTRAN, M.H.R. (orgs.) Escrevendo a história da ciência: tendências, propostas e discussões historiográficas. São Paulo: Livraria da Física: 2004, p.115-145.

NUNES, J. C. O. A Elasticidade e a Mecânica Relativista. 139 f. Dissertação (Mestrado em Matemática) - Instituto Politécnico de Bragânça, Universidade do Minho, Braga, 2003.

PRAIA, J.; CACHAPUZ, A.; GIL-PÉREZ. A hipótese e a experiência científica em educação em ciência. In: CACHAPUZ, A. GIL-PÉREZ, D.; CARVALHO, A.M.P. PRAIA, J.; VILCHES, A. (orgs.). A necessária renovação do Ensino de Ciências. 3.ed. São Paulo: Cortez, 2011.

PORTO, C. M.; PORTO, M. B. D. S. M. Uma visão do espaço na mecânica newtoniana e na teoria da relatividade de Einstein. Revista Brasileira de Ensino de Física, v. 30, n. 1, p.1603.1-1603.8, 2008.

RIFFEL, A. R.; Uma Introdução a Teoria da Relatividade Especial. Material didático elaborado para a disciplina de Relatividade Especial do curso de Física Licenciatura a Distância UFSM/UAB. Santa Maria, 2010. 